\title{
Helicopter emergency medical rescue for the traumatized: experience in the metropolitan region of Campinas, Brazil
}

\author{
Resgate aeromédico a traumatizados: experiência na região metropolitana de \\ Campinas, Brasil
}

Ricardo Galesso Cardoso"; Carina Fontana Francischinl²; Jorge Michel Ribera'; Ricardo Vanzetto"; Gustavo Pereira Fraga, TCBC-SP3

A B S T R A C T

\begin{abstract}
Objective: To analyze the profile of patients served by the air medical rescue system in the Metropolitan Region of Campinas, evaluating: triage and mobilization criteria; response time; on-site care and transport time; invasive procedures performed in the Pre-Hospital Care (PHC); severity of patients; morbidity and mortality. Methods: We conducted a prospective, descriptive study in which we analyzed medical records of patients rescued between July 2010 and December 2012. During this period, 242 victims were taken to the HC-Unicamp. Of the 242 patients, 22 were excluded from the study. Results: of the 220 cases evaluated, 173 (78.6\%) were male, with a mean age of 32 years. Blunt trauma was the most prevalent (207 cases $-94.1 \%$ ), motorcycle accidents being the most common mechanisms of injury (66 cases $-30 \%$ ), followed by motor vehicle collisions ( 51 cases $-23.2 \%$ ). The average response time was $10 \pm 4$ minutes and the averaged total pre-hospital time was $42 \pm 11$ minutes. The mean values of the trauma indices were: RTS $=6.2 \pm 2.2$; ISS $=19.2 \pm 12.6$; and TRISS $=0.78 \pm 0.3$. Tracheal intubation in the pre-hospital environment was performed in 77 cases (35\%); 43 patients (19.5\%) had RTS of 7.84 and ISSd"9, being classified as over-triaged. Of all patients admitted, the mortality was 15.9\% (35 cases). Conclusion: studies of air medical rescue in Brazil are required due to the investments made in the pre-hospital care in a country without an organized trauma system. The high rate of over-triage found highlights the need to improve the triage and mobilization criteria.
\end{abstract}

Key words: Trauma. Emergency medical services. Rescue work. Air ambulances.

\section{INTRODUCTION}

I is known that the survival of a trauma victim is directly related to the speed with which the same is subjected to the appropriate definitive treatment ${ }^{1}$. If the patient with serious injuries enters the emergency room and undergoes surgery in the shortest possible time, survival chances will be much greater, since the effective control of bleeding is earlier, and the trauma-related coagulopathy and hypothermia will have lower chances of ensuing permanently. Faced with this reality, the need for rapid and appropriate care in the pre-hospital phase is imperative. Factors such as time of day, traffic, distribution of ambulances and location where the patient will be taken directly influence the time of pre-hospital care. Seeking to establish an effective treatment in the shortest possible time, we tried to combine the possibility of access to the victim, initial treatment and rapid transport by air rescue, with use of the helicopter.

Historically, the use of aircrafts for aeromedical rescue mission began in 1870, in the Franco-Prussian War, during which the first cases were reported in which 160 injured were rescued by hot air balloons ${ }^{2}$. During World War I, transporting of injured by planes started, but the lack of an adequate aircraft, with enough space and security, made the operation extremely difficult ${ }^{3}$. In World War II, the Air Ambulance was recognized as an essential part of the treatment and recovery of the wounded, and was widely used, with the formation of squads geared just for this type of mission, using adapted troops-transport aircrafts, and introducing the concept of specialized crew, consisting for the most part by Flight Nurses of the United States Air Force, receiving specific training for aeromedical transport of patients. In the final years of the Second Great War, between 1943 and 1945, the average patients transported was more than 100,000 per month, 4,704 traumatized having come to be transported in a single day 3. In 1950, during the Korean War, the use of the helicopter as a means of rescue and transport of injured was consecrated, 20,000 military personnel having benn transported. In the Vietnam War that number increased to more than 370,000 soldiers ${ }^{4}$.

1. Rescue and Emergency Care Group (GRAU), Health Secretariat, São Paulo State - SP, Brazil; 2. Faculty of Medical Sciences, State University of Campinas (UNICAMP), Campinas, SP, Brazil; 3. Discipline of Trauma Surgery, Department of Surgery, Faculty of Medical Sciences, State University of Campinas (UNICAMP), Campinas, SP, Brazil. 
Mirroring on the success of the military rescue operations, the first civilian air medical services associated with a trauma center was successfully initiated in 1973, in Maryland, United States ${ }^{5}$. Since then the use of helicopters in aeromedical missions has increased considerably, expanding to many countries, such as UK ${ }^{6}$, Germany ${ }^{7}$, and Japan ${ }^{8}$.

In Brazil, the first air Search and Rescue (SAR) service was officially established in December 1957, with the II Squadron of the Tenth Aviation Group, "Pelican Squadron", of the Brazilian Air Force. In the State of São Paulo, the Military Police initiated the use of a helicopter with the "João Negrão" Air Police Group (GRPAe) on August 15, 1984, with two Squirrel-type aircrafts in policing, rescueing, observation, transporting and monitoring traffic in the metropolitan region of São Paulo. Despite the start of air operations in 1984, it was only in May 1989, after the implementation of the Emergency Rescue System, that an agreement was reached between the State Secretariat of Public Safety and the State Secretariat of Health (SES), with the beginning of the areomedical rescue (AR) missions in the GRPAe ${ }^{9,10}$. The Rescue System provides Primary PreHospital Care (PHC) service, preferably to victims of traumatic urgencies and emergencies, either through terrestrial or aerial vehicles.

The aeromedical rescue initially remained restricted to the metropolitan region of São Paulo. With increasing population density in the state and the consequent increase in urban violence, the demand for specialized pre-hospital care has grown increasingly, which led to the expansion of the service, the advanced Life Support (ALS) of the Rescue System in the city of Campinas having been inaugurated June 30,2010, in its Base fro air Police (BRPAe Campinas), providing care both by land, using a rapid intervention vehicle (VIR), and by air, with the helicopter ${ }^{11}$.

The rescue is called by the number 193, of the Fire Department Operations Center (COBOM). The regulator physician and the operations officer are responsible, by means of the information received, for dispatching a suitable vehicle, be it a BLS car (Rescue Unit - UR), manned by three firefighters with paramedical training, or the ALS car, which can be either a conventional ground vehicle, called ASU (Advanced Support Unit), which is manned by a doctor, a nurse and a driver firefighter, or a helicopter, named Eagle, manned by a doctor, nurse and two pilots. It is also for the regulator physician to indicate the best hospital resource for every type of medical care, according to hospitals' regionalization and hierarchization.

The limited hours of operation of the rescue, restricted to the interval between sunrise and sunset (by definition, daytime flights), is an internal regulation of GRPAe, aiming at operational safety, since these missions landings are performed in "restricted areas" which are not prepared and have small size, as sports fields, parking lots, streets and parks. In those places there may be obstacles such as tree branches, power lines or poles, as well as the floor may be uneven or flooded, conditions that make nocturnal visual operation extremely risky during takeoff and landing.

In the configuration of the aircraft for aeromedical rescue, the victim, when loaded, is positioned on a stretcher or board on the rear seat, in the transverse direction. Doctor and nurse position themselves kneeling on the floor of the aircraft. The lack of mobility due to the position, as well as the reduced cabin space, prevent much of the ALS procedures, such as endotracheal intubation, chest compressions, cardiac defibrillation and thoracic drainage. This directly influences the conduct of the medical staff, because one should try to predict the need for the most complex ALS procedures, so they are all performed prior to shipment, with no transport of unstable patients.

Although $A R$ is well established in several countries, including Brazil, especially in the State of São Paulo, the national scientific literature on the subject is still very scarce. Most publications found are related to nursing care and the performance of the onboard nurse during transportation and aeromedical rescue ${ }^{12,13}$. In 2011, Nardoto et al. published a profile of victims assisted by State of Pernambuco AR service ${ }^{14}$. This report, however, provided data concerning only $\mathrm{PHC}$, without information on the intrahospital care and evolution of patients. The present study presents the results of an AR Brazilian service, assessing multiple aspects of trauma victims care, from the PHC till definitive treatment.

\section{METHODS}

We conducted a prospective, descriptive study, in which we evaluated the charts of pre-hospital treatment filled by the physician of the GRAU rescue group Eagle crew, as well as hospital records of the same patients, through research in the Service of Medical Records (SAM) of the Clinics Hospital (HC), State University of Campinas (UNICAMP).

The area of operation of the rescue missions covers a distance of 20 minutes flying time from the base. At the far end of this area, the round trip already consumes about 40 minutes, leaving little time available to attend the scene, given the impossibility of carrying out complex ALS procedures during the flight.

In 20 minutes of flight, approximately $65 \mathrm{~km}$ are covered, considering the average speed of the helicopter, which is 110 knots (about $200 \mathrm{~km} / \mathrm{h}$ ), amounting to 50 counties, including those that comprise the metropolitan region of Campinas and others in the vicinity, and every local road network. The estimated population of the region is approximately three million people, in both urban and rural areas.

Patients included were the ones seen by the Campinas BRPAe AR team, transported by the helicopter 
Eagle to the HC-Unicamp, a trauma referral center in the region and the location where the vast majority of patients is taken. There was no distinction of age, and we excluded patients found dead at the scene or victims of nontraumatic emergencies.

The dispatch of the Campinas BRPAe AR team is done through contact between the region $\mathrm{COBOM}$ and the team GRAU/GRPAe on duty, who will assess the severity of the case, distance, weather, and the possibility of landing at the scene. Once the aircraft is chosen, after landing the crew performs the assessment and on-site service, and may opt for air transport or for referencing the patient for land transport if the injuries are minor or the clinical conditions very unstable, with risk of clinical deteriorating and / or cardiac arrest during the flight.

The dispatch of the rescue aircraft must follow the criteria present in two Standard Operating Procedures (SOP) of the Fire Department: SOP 01-02 - Advanced Support Request; and SOP 01-04 - Advanced Air Support. In SOP 01-02 the ALS dispatch criteria are: airway obstruction; acute respiratory failure; respiratory or cardiac arrest; victim in shock; severe politrauma; politraumatized trapped in the wreckage or in places hard to reach (landslides, burials, bluffs, isolated locations); multiple victims; victims with limbs trapped in machinery, hardware or debris; traumatic amputation of limbs close to the body; penetrating injuries to head, chest or abdomen; unconscious victims; Glasgow Coma Scale (GCS) less than 13; fall from height over seven meters; major bleeding; and drowning. In SOP 01-04 the guidelines are: Follow the same criteria of the terrestrial ALS dispatch, observing the presence of at least one of the following conditions: lack of land ALS vehicle near the occurrence; arrival of the terrestrial vehicle to the place of occurrence hampered by major congestion, flooding, lack of trafficable route, big bluffs or large distance between the place of occurrence and the hospital. The conditions mandatory for all dispatches are: time between sunrise and sunset; presence of firefighter vehicle at the scene, or of a technically qualified team to evaluate the need for air support and bilateral radio contact between the land vehicle and the aircraft.

We analyzed information on gender, age, mechanism of injury, location (municipality) of occurrence, time of service, appropriateness of dispatch criteria, invasive procedures performed in the PHC, anatomical location of injury, severity of patient, morbidity and mortality.

As attendance times, we evaluated (in minutes): time between the call and the arrival at the scene (response time); time at the scene, considered as the time between the arrival of the aircraft at the occurrence site and the beginning of the patient transportation to the hospital; time of pre-hospital care, considered as the interval between the arrival at the scene and the arrival at the hospital; total time of pre-hospital care, defined as the time between the injury and the patient's arrival at the hospital. To calculate the total pre-hospital time we considered the initial time as the moment the team had been deployed, since the time between the actual occurrence and the request reaching the operations center via telephone is not amenable to precise measurement, being, in most cases, a very short.

The appropriateness of the dispatch criteria was considered correct when the patient met one or more of the criteria present in the SOP 01-02 and at least one criterion SOP 01-04.

We also analyzed the invasive procedures performed in the pre-hospital setting, such as intubation, venous access and chest drainage. To evaluate the severity of patients, we analyzed vital signs and lesions presented, both by clinical examination and by means of imaging exams and intraoperative findings, with calculation of indices of trauma: Revised Trauma Score (RTS) ${ }^{15}$, Injury Severity score (ISS) ${ }^{16}$ and Trauma Injury Severity Score (TRISS) ${ }^{17}$ for each patient.

The adequacy of SOP criteria was evaluated by analyzing the data of the pre-hospital charts and GRPAe flight reports. We considered patients with "severe trauma" those with ISS e" 25, "unconscious victims" were patients with GCS $<9$, "shock" when SBP $<90 \mathrm{mmHg}$ and "multiple victims" when accidents involved three or more victims. The absence of a land ALS near the occurrence was considered taking into account the location and/or the presence of ALS or firefighters bases in the region.

We also analyzed patient outcomes in relation to length of stay, time of discharge or death. Data on hospitalization of patients were obtained from the medical and nursing staff, surgical reports and results of laboratory and imaging tests, present in the hospital records.

The study was approved by the Ethics in Research Committee of the Faculty of Medical Sciences, Unicamp, through the opinion 1257/2010 and CAAE: 0987.0.146.00010.

\section{RESULTS}

We assessed medical charts and records of patients treated between July 2010 and December 2012 . During this period, 242 victims were assisted by the $A R$ staff and taken to the HC-Unicamp, with an average of about one call every three analyzed days. Of the 242 patients, 22 were excluded for being victims of nontraumatic emergencies or due to faulty and / or incomplete filling of records; the data of 220 patients were analyzed; 173 (78.6\%) were male, with an average age of 32 years and a median of 29. Blunt trauma was the most frequent, occurring in 207 (94.1\%) victims, and of these, $66(30.0 \%)$ were involved in motorcycles accidents, $51(23.2 \%)$ were involved in automobile colisions, $32(14,5 \%)$ in falls from height, 31 (14.1\%) automobile-pedestrian colisions. Penetrating trauma occurred in 13 cases (5.9\%). The types of trauma mechanisms can be observed in Table 1. 
The place of occurrence was the city of Campinas in 162 cases $(73.6 \%)$, while the remaining 58 patients were treated at other municipalities in the region, especially the city of Indaiatuba, with 12 cases (5.5\%), Americana, seven cases (3.2\%) and Valinhos, with six cases (2.7\%). The average response time was 10 minutes, ranging between three and 48 (Figure 1).

A long response time, above the maximum predicted of 20 minutes, occurred in 13 calls (5.9\%). Most often, these occurrences were located outside the metropolitan region of Campinas. However, only one of them happened outside the limit established for the area of operation (within 20 minutes flying time from the base), near the city of Sorocaba.

The average service time on scene was 21 minutes, ranging between three and 88 (Figure 2).

There were some quite long-lasting services, eight (3.6\%) between 41 and 60 minutes, and four (1.8\%) over 60 minutes, the longest with 88 minutes. This increase in time occurred in patients whose conditions or mechanism of injury did not allow immediate transport. Six of them $(2.7 \%)$ were in hard to reach places: ravines, ditches and wells. These locations often pose risk to the medical staff, who must wait until the victims are removed to a safe place to start treatment. Other four $(1.8 \%)$ were trapped in the wreckage of vehicles, and two of them $(0.9 \%)$ had limbs in stuck in machines. In these last two situations, although he tpartial access to the victim is possible, allowing the performance of life saving procedures like securing the airway, thoracic puncture and venous access, the total disentangling of the patient can be quite complex and difficult, demanding resources and materials sometimes not immediately available, as well as the use of delicate and laborious techniques, which eventually greatly prolongs the time at the scene.

The pre-hospital care time, which is the sum of

Table 1 - Number of cases and percentage according to the mechanism of trauma.

\begin{tabular}{lcc}
\hline Mechanism of trauma & $\begin{array}{c}\text { Frequency } \\
(\mathrm{n})\end{array}$ & $\begin{array}{c}\text { Percentage } \\
(\%)\end{array}$ \\
\hline Motorcycle & 66 & 30.0 \\
Automobile & 51 & 23.2 \\
Fall from height & 32 & 14.5 \\
Pedestrian collision & 31 & 14.1 \\
Crushing & 9 & 4.1 \\
Burn & 8 & 3.6 \\
Stab wound & 6 & 2.7 \\
Gunshot wound & 5 & 2.3 \\
Drowning & 3 & 1.4 \\
Bicycle accident & 2 & 0.9 \\
Impalement & 2 & 0.9 \\
Other & 5 & 2.3 \\
Total & 220 & 100.0 \\
\hline
\end{tabular}

the time at the scene to the time of transport to the hospital, averaged 31 minutes, ranging between eight and 97. The total pre-hospital time, which was regarded as the time of occurrence of the trauma until the arrival to the ER, averaged 42 minutes, ranging from 14 to 109 . The frequency with which the dispath criteria were used can be seen in Figures 3 and 4 . Some patients had injries that allowed the inclusion of more than one criterion.

We found that 57 patients (25.9\%) did not fit in any of the items on SOP 0102 and nine patients (4.1\%) did not fit the criteria of SOP 01-04.

Regarding the location of the injury, not considering external lesions, there was predominance of trauma of the extremities, present in 128 (58.2\%) victims, followed by trauma of the head and neck (113 patients $51.4 \%$ ), chest (74 patients $-33.6 \%$ ), abdomen / pelvis (42 patients $-19.1 \%$ ) and face (41 patients - 18.6\%).

Thirty-three patients $(15 \%)$ had SBP $<90 \mathrm{mmHg}$ on admission, and 77 (35\%) had GCS $<9$, all these having been intubated already in the pre-hospital environment. One hundred seventeen patients (53.2\%) were operated after admission, and 18 (8.2\%) underwent nonoperative treatment (TNO) of abdominal parenchymal visceral injuries.

The mean RTS was $6.2 \pm 2.2$, and 123 patients (55.9\%) had a score of 7.84 . Of these, 43 patients (19.5\%)

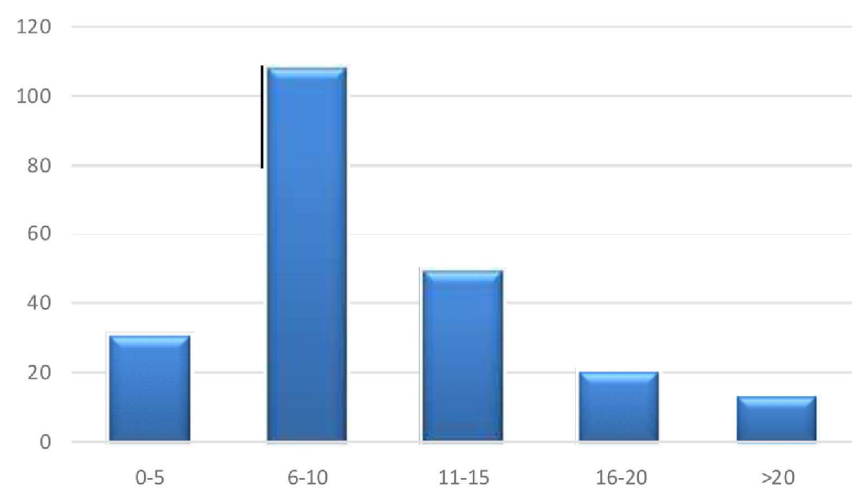

Figure 1 - Number of cases according to response time in minutes.

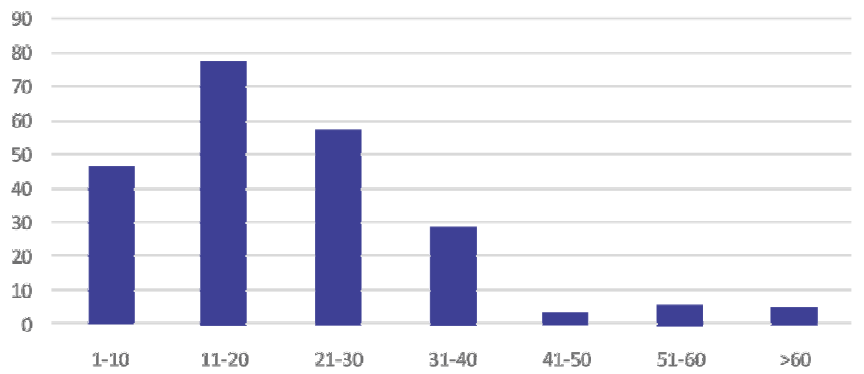

Figure 2 - Number of cases according to the average time on the scene in minutes. 
had ISS d" 9, being classified as "over-triaged". The average ISS was $19.2 \pm 12.6$, median 17.0, with 98 patients (44.6\%) displaying ISS d" 15, and 81 (36.8\%) had calculated TRISS ISS e" 25.0 averaged $78.5 \%$, and a median of $99 \%$. Fortyfour patients (20\%) had TRISS $<50 \%$, and $22(50 \%)$ died. There were also 13 deaths in patients with TRISS $>50 \%$.

Of all patients admitted, 185 (84.1\%) were discharged after a mean hospital stay of 17.8 days, and 44 (23.7\%) left the hospital in less than 24 hours, and of these, $26(14.1 \%)$ left the ER within 12 hours after admission.

There were 35 deaths (15.9\%), 12 (34.3\%) within six hours of arrival to the $E R$, and four in the period between six and 24 hours after entering the hospital, which makes a total of 16 patients (45.7\%) who died within 24 hours after admission.

\section{DISCUSSION}

Screening criteria for the helicopter dispatch have been the subject of studies since the implementation of the first services. Efforts are made to avoid the occurrence of errors, which can both be classified as "undertriage", a

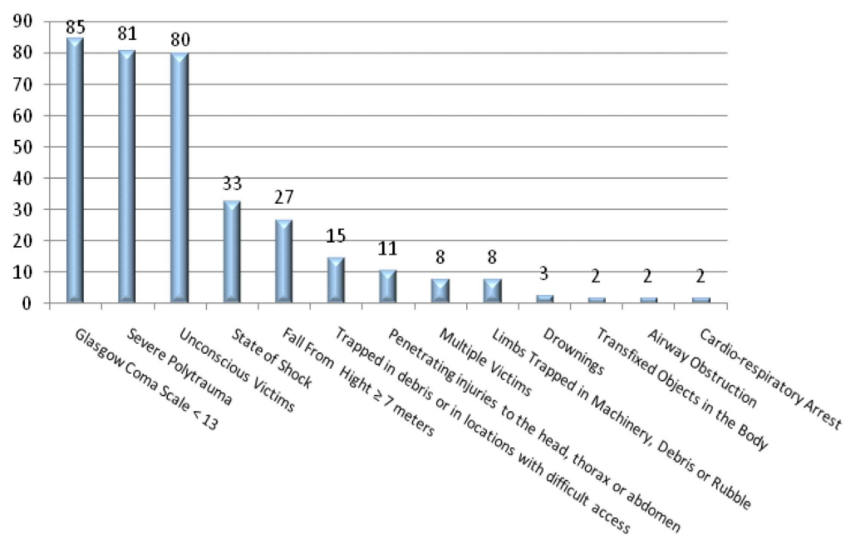

Figure 3 - Frequency (n) of use of the SOP 01-02 criteria.

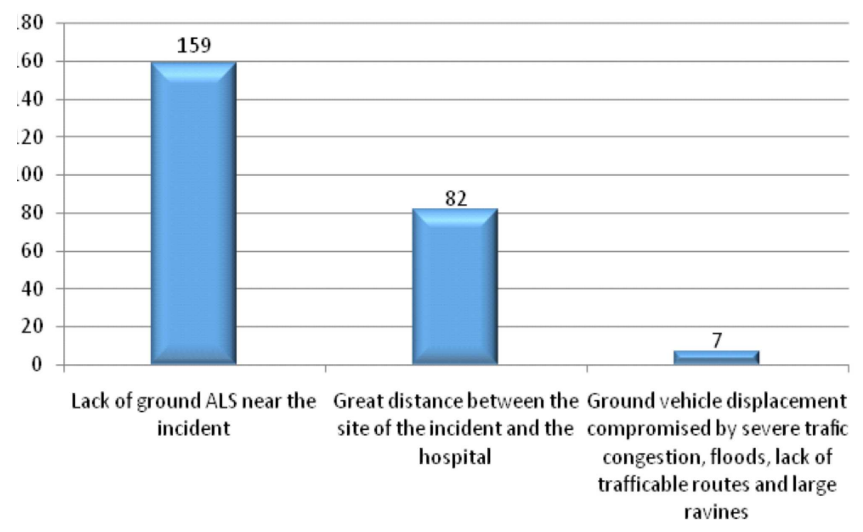

Figure 4 - Frequency (n) of use of the SOP 01-04 criteria. situation in which patients with severe injuries are classified as having mild trauma, generating a significant increase in morbidity and mortality, as well as overtriage, which occurs when victims with less serious injuries are classified as having more severe ones, resulting in overload of the highcomplexity care reference services, and consequently an increase in the costs involved in patient care, as well as leading to greater exposure, both of patients and teams, to the risks inherent of the use of the aircraft in this type of mission. According to the Committee on Trauma of the American College of Surgeons ${ }^{18}$, an undertriage rate of around $5-10 \%$ is considered inevitable, and comes with an overtriage rate of around $30-50 \%$. Other studies have shown that overtriage-related errors can be even bigger, hovering around $50-90 \%{ }^{19}$, and may occur in dispatching of both land ALS and AR teams.

Multiple factors may be involved in the decision process: mechanism of injury, patient's physiological conditions, distance from the reference trauma center, need for ALS procedures, weather conditions, among others. Aiming to systematize the criteria for triage of trauma patients to identify patients who may have serious or potentially serious injury and provide them with the ideal level of treatment and support, both pre- and in-hospital, in 2006 the Center for Disease Control and Prevention (CDC) published an algorithm for triage of patients victims of trauma ${ }^{20}$, with last update in 2011 , which is divided into four stages, according to physiological parameters of the patient, anatomical location and nature of injuries, mechanism and kinematics of trauma, and other specific conditions, both of the patient and of the trauma system. Steps 1 and 2 identify patients with severe injuries, who will most likely benefit from the highest level of treatment possible. In steps 3 and 4 other factors are analyzed, which, when associated with the judging criteria from the medical regulation officer and the peculiarities of the local trauma system, can direct the transport of the patient to a center of greater or lesser complexity.

One of the first initiatives to systematize the dispatch of AR teams was made by Black et al. who published an algorithm in which one first took into account the contraindications to air travel, such as adverse weather conditions, harsh environment (risks to staff or the aircraft), uncooperative patients or accidents with hazardous materials ${ }^{21}$. Then were analyzed the patient's condition in relation to compromised airway and breathing, signs of shock or neurological disorders, thus evaluating the need for interventions in advanced life support and transport to a trauma center. Despite fairly consistent in relation to the criteria used, the work only suggests the application of the algorithm, without making any assessment of its practical applicability and results.

In a systematic review, Ringburg et al. concluded that the dispatch criteria based on the trauma mechanism, age and comorbidities of patients have low positive predictive value and lead to significant overtriage rates ${ }^{22}$. 
The physiological parameters and anatomical location of the injuries were those with greater accuracy, especially the criterion "loss of consciousness", or low Glasgow Coma Scale, which had a sensitivity of $93-98 \%$ and specificity of 85-96\%.

The Committee on Trauma of the American College of Surgeons recommends using the guidelines published by the National Association of EMS Physicians (NAEMSP), which include parameters such as the mechanism of injury, physiological data, anatomical lesions and special considerations, such as children, elderly and pregnant women ${ }^{23}$.

As in the algorithm from the CDC and in the dispatching guidelines from NAEMSP, the criteria present in the of the São Paulo Military Police Fire Brigade SOP 0102 also include physiological parameters (respiratory failure, cardiac arrest, signs of shock and level of consciousness), type and anatomic location of injury (airway obstruction, penetrating injuries to head, chest or abdomen, amputations, major bleeding), mechanism of injury (victims trapped in hardware, members trapped in machinery or debris, body-piercing objects, drowning, falling from height over seven meters) and special situations (multiple victims, places hard to reach).

Although they used very similar criteria, the ones present in SOP 01-02, in some aspects are less specific and more subjective in relation to the CDC and NAEMSP protocols, as they do not specify, for example, the parameters to be used to define shock or acute respiratory failure (present in the other Standard Operating Protocol SOP 01-04) and include the term "severe polytrauma", which has no specific definition in any other Standard Operating Protocol, which can generate different interpretations according with every rescuer who is providing care.

This subjectivity, as well as the different perceptions of seriousness on the part of the rescue teams, can generate triage errors, mostly related to overestimation of gravity, generating overtriage and excessive use of specialized (and expensive) resources, as previously mentioned. On the other hand, it may be noted that the criteria of NAEMSP and CDC are also not free from subjectivity, as in "Ground provider perception of significant damage to patient's passenger compartment", present in the NAEMSP of criteria and in the latest CDC guidelines: "when in doubt, transport to a trauma center." These two recommendations may also lead to different interpretations according to the level of knowledge and experience of the respondents, and may also generate increased rates of overtriage.

Although the NAEMSP criteria are more detailed and comprehensive than the COBOM ones, they include injuries or situations where the potential severity or risk of death may not necessarily be high, as in items "rib fracture below the nipple line", "belt signal or other lesions of the abdominal wall " and "open fracture of long bones".
Regarding the kinematics of trauma, we also found in the NAEMSP table criteria on which the level of severity of the patient can be quite variable, as in "pedestrian or cyclist hit by a motor vehicle."

The triage criteria adopted by the services seek to identify patients at higher gravity, with life-threatening injuries, which theoretically would benefit from a quick service by a team of advanced support, as well as rapid transport to the trauma center. Within this context, we have several factors to be analyzed, such as response time / service time, the presence of advanced support team in the place of the accident and the severity of patients transported.

The idea that the rescue is faster when done by helicopter when compared with ground ambulance seems obvious, and is one of the main arguments that justify the use of AR. However, in a study conducted by Diaz et al., the Air service was faster than the land one only in distances over ten miles (approximately 16 kilometers) ${ }^{24}$. This can be explained by the higher number of ambulance ground bases in the central areas of the cities, which decreases the chance of a prolonged need for travel to the accident site. In addition, there are more and larger buildings in downtown areas, which leads to greater difficulty in finding safe landing sites, which may prolong the response time or even prevent the continuation of the mission. In that same study ${ }^{24}$, the average turnaround time of terrestrial teams was 7.4 minutes, while the helicopter one was 24.7 minutes. In our study, of the 220 patients, 168 (76.4\%) were rescued in the metropolitan region of Campinas, and the average turnaround time was ten minutes, much lower than found by Diaz et al. ${ }^{24}$. Considering the speed of the aircraft, we have that the average attendance was done about $33 \mathrm{~km}$ away from the base. Although the majority of calls have been made in the urban environment, where the access to land teams is theoretically easier, the average distance was more than twice that of Diaz et al., who reported the switching from land rescue to air one to be advantageous ${ }^{24}$, suggesting that our dispatches are suitable from the standpoint of response time and distance of occurrences.

The presence of a doctor at the scene can be one of the factors that justify the use of air medical rescue, because the range of procedures to be offered to patients, many of them essential to the maintenance of life, is considerably higher. The benefit of the physician's presence at the scene was proven by Frankema et al., who showed an increase in the chance of survival of patients treated by the air rescue medical staff when compared with land service ${ }^{25}$.

In our study, all patients with Glasgow Coma Scale less than 9 were submitted to tracheal intubation in the pre-hospital environment. Also, nine thoracic drainages and 13 dissections of peripheral veins were performed. These procedures are carried out by physicians, are classified as 
life saving interventions and can mean the difference between a lethal outcome and patient survival.

The possibility to perform invasive and complex procedures in the pre-hospital environment can also have a negative effect, the increased time at the scene. Ringburg et al. compared the time of service in the scene between $A R$ (with doctors) and land (no doctor) teams, correlating it with the mortality of patients attended by an AR service in the Netherlands ${ }^{26}$. They found a significant difference between the two, the average time on scene of AR teams being 35.4 minutes, while the one of land teams was 24.6 minutes. Despite this difference, after correcting for the characteristics and severity of trauma patients, the mortality rate was not influenced by the time at the scene. In another study by Dissman and Le Clerc in an AR service in England countryside, they found no difference in time at the scene between AR teams with doctors and ground teams with paramedics, and the average time was 25 minutes ${ }^{27}$. In this study, the factor that most contributed to the increase in time at the scene was attending to victims trapped in wreckage, which accounted on average for 23 minutes of total attendance.

The average service time at the scene found in our study was 21 minutes, below the average observed in previous studies, and quite reasonable, considering the complexity of frequently performed procedures and the difficulty inherent to the pre-hospital setting.

A study by Melton et al., involving three services of aeromedical rescue in the England countryside, showed an average ISS of 12 among their patients, $41 \%$ of them having been discharged directly from the emergency department (mean ISS of 1 to the latter group) ${ }^{28}$. Shatney et al. conducted a retrospective analysis of 947 patients taken by AR to a trauma center in California over a period of ten years and found an average ISS of 8.9, only 148 of them $(15.6 \%)$ having ISS $>15{ }^{29}$. In a meta-analysis published by Bledsoe et al., comprising 22 publications involving assessment of trauma scores (ISS, and TRISS) of a total of 31,244 patients treated by aeromedical rescue teams, 18,629 (60\%) had ISS d" 15 , and in another group of 6,328 patients, 4,414 (69.3\%) had TRISS e" 0,90 ${ }^{30}$. Findings common to these studies are that air medical rescue services have the tendency to overtriage patients, serving and transporting victims without serious injuries that do not endanger life, thus increasing costs of emergency systems with the use of unnecessary resources. Thay are unanimous in concluding that, for this problem to decrease, more effective triage mechanisms should be developed.

In our study, the mean ISS found was 19.2, and 79 patients $(35.9 \%$ ) had ISS $>25$, which shows a higher level of severity. Nevertheless, 98 patients (44.5\%) had ISS $f 15$.

When analyzing the trauma indices, both for physiological (RTS) as for anatomical (ISS) parameters, we conclude that a significant portion of the victims attended by the service could be classified as overtriaged.

In our study, the calculated TRISS averaged $78.5 \%$, and 112 patients (50.9\%) obtained the value of $99 \%$. The high degree of probability of survival may be due to the low severity of injuries or to the physiological parameters obtained being close to normal, as well as the two associated factors. It is worth noting that of the 220 patients in our study, 98 (44.5\%) had ISS $\mathrm{f} 15$, and 123 (55.9\%) had RTS scores of 7.84. Thus, we observe that the proportion of patients with no serious injuries and with high probability of survival is quite significant, around $50 \%$.

Still analyzing the severity of patients, we have that 117 of them (53.2\%) were operated after admission, and $18(8.2 \%)$ underwent non-operative treatment of injuries of abdominal parenchymal viscera. Thus, at least 135 patients $(61.4 \%)$ required in-hospital level specialized care and procedures, having justified their transport to the referral center for trauma.

Of all the victims attended, death occurred in 35 (15.9\%), and $12(34.3 \%)$ died within six hours of arrival in the emergency room. Despite the presence of many patients with a high chance of survival, 44 victims (20\%) displayed TRISS $<50 \%, 22$ (50\%) having died. There were also 13 deaths in patients with TRISS $>50 \%$. Of the patients who died, 11 were operated, and 24 died without being operated. Of the 18 patients undergoing Non-operative treatment (NOT), 14 were discharged.

Of all patients admitted, 185 (84.1\%) were discharged, $44(23.7 \%)$ leaving the hospital in less than 24 hours; 65 (29.5\%) were discharged without being operated or being submitted to non-operative treatment of abdominal injuries.

The AR service in the city of Campinas is the first in a base in the interior of São Paulo State, and despite not having a high volume of attendance when compared with American or European services, it presents results quite similar to those, and in some cases, even better, when analyzed indices of severity of disease, such as response time and outcome.

We conclude that the aeromedical rescue is an important tool in the trauma care systems, but there was a high rate of overtriage, which demonstrates the need for improvement of the screening and dispatch criteria, as well as to intensify the training and familiarization of emergency teams with these protocols.

Although the focus of this study was not to analyze the influence of AR on survival, nor the proof of its cost effectiveness, results such as the ones described above serve as stimulus for further specific and thorough study on the subject in order to determine which and how the factors involved in the context of AR (response-time, presence of medical staff, transportation to the center of reference, etc.) may influence the prognosis and outcome of the patients. 


\title{
R E S U M O
}

\begin{abstract}
Objetivo: analisar o perfil de doentes atendidos pelo sistema de resgate aeromédico na Região Metropolitana de Campinas, avaliando critérios de triagem e acionamento; tempo-resposta, tempo de atendimento e de transporte; procedimentos invasivos realizados no APH; gravidade dos doentes; morbidade e mortalidade. Métodos: estudo prospectivo descritivo, no qual foram analisados prontuários e fichas médicas de pacientes atendidos entre julho de 2010 e dezembro de 2012. Nesse período, 242 vítimas foram levadas ao HC-Unicamp. Dos 242 pacientes, 22 foram excluídos do estudo. Resultados: dos 220 casos avaliados, 173 (78,6\%) eram do sexo masculino, com média de idade de 32 anos. O trauma contuso foi o mais prevalente (207 casos - 94,1\%), sendo os mecanismos de trauma mais frequentes os acidentes de motocicleta (66 casos - 30\%) e colisões automobilísticas (51 casos - 23,2\%). O tempo-resposta médio foi $10 \pm 4$ minutos e tempo total de pré-hospitalar teve média de $42 \pm 11$ minutos. Os valores médios dos índices de trauma foram: RTS =6,2 $\pm 2,2 ;$ ISS = 19,2 $\pm 12,6$; e TRISS =0.78 \pm 0.3 . Intubação orotraqueal no pré-hospitalar foi realizada em 77 casos (35\%) e 43 doentes (19,5\%) tinham RTS de 7,84 e ISSd"9, sendo classificados como "supertriados". Do total de pacientes admitidos, a mortalidade foi 15,9\% (35 casos). Conclusão: estudos de resgate aeromédico no Brasil são necessários devido aos investimentos realizados no pré-hospitalar num país sem sistema de trauma organizado. O elevado índice de supertriagem encontrado evidencia a necessidade de aperfeiçoamento dos critérios de triagem e acionamento.
\end{abstract}

Descritores: Trauma. Atendimento de emergência pré-hospitalar. Trabalho de resgate. Resgate aéreo.

\section{REFERENCES}

1. Blackwell TH, Kaufman JS. Response time effectiveness: comparison of response time and survival in an urban emergency medical services system. Acad Emerg Med. 2002;9(4):288-95.

2. Dorland P, Nanney J, Center of Military History. Dust off: Army aeromedical evacuation in Vietnam. Washington, D.C.: Center of Military History For sale by the Supt. of Docs., U.S. G.P.O.; 1982. vi.

3. Hurd WW, Jernigan JG. Aeromedical evacuation: management of acute and stabilized patients. New York: Springer; 2003. xv.

4. Whitcomb DD. Call sign "Dustoff": a history of U.S. Army aeromedical evacuation from Conception to Hurricane Katrina. Frederick, MD: Borden Institute; 2011. cxxix.

5. Cowley AR, Hudson F, Scanlan E, Gill W, Lally RJ, Long W, et al. An economical and proved helicopter program for transporting the emergency critically ill and injured patient in Maryland. J Trauma. 1973;13(12):1029-38

6. Nicholl JP, Brazier JE, Snooks HA. Effects of London helicopter emergency medical service on survival after trauma. BMJ. 1995:311(6999):217-22

7. Struck MF, Weber S. The historical development of helicopter emergency medical services in the German Democratic Republic Air Med J. 2010;29(6):294-9.

8. Matsumoto H, Mashiko K, Hara Y, Sakamoto Y, Kutsukata N, Takei $K$, et al. Effectiveness of a "doctor-helicopter" system in Japan. Isr Med Assoc J. 2006;8(1):8-11.

9. São Paulo. Governo do Estado de São Paulo. Secretaria de Segurança Pública. Diário Oficial do Estado. Resolução Conjunta SSSSP-42. Sect. Executivo I, pag 14, 23 de maio (1989).

10. Martini A, Rozolen Jr P. Atendimento pré-hospitalar no Brasil e no mundo: histórico. In: Feriani G, Ribera J, Damasceno M, Rozolen Jr P, Cardoso R, editores. Pré-Hospitalar GRAU. Barueri, SP: Manole; 2013. p. 3-12.

11. Cardoso RG, da Costa L, Lisak S. Resgate Aeromédico. In: Fraga GP, Sevá-Pereira G, Lopes LR, editores. Atualidades em Clínica Cirúrgica - Intergastro e Trauma 2011. São Paulo: Atheneu; 2011. p. 53-62.

12. Scuissiato DR, Boffi LV, da Rocha Rda R, Montezeli JH, Bordin MT, Peres AM. Compreensão de enfermeiros de bordo sobre seu papel na equipe multiprofissional de transporte aeromédico. Rev Bras Enferm. 2012;65(4):614-20

13. Rocha PK, do Prado ML, Radünz V, Wosny Ade M. Assistência de enfermagem em serviço pré-hospitalar e remoção aeromédica. Rev Bras Enferm. 2003;56(6):695-8.
14. Nardoto EML, Diniz JMT, Cunha CEG. The profile of victims attended by the Pernambuco pre-hospital air service. Rev esc enferm. 2011;45(1):237-42.

15. Champion HR, Sacco WJ, Copes WS, Gann DS, Gennarelli TA, Flanagan ME. A revision of the Trauma Score. J Trauma. 1989;29(5):623-9.

16. Baker SP, O'Neill B, Haddon W Jr, Long WB. The injury severity score: a method for describing patients with multiple injuries and evaluating emergency care. J Trauma. 1974;14(3):187-96.

17. Boyd CR, Tolson MA, Copes WS. Evaluating trauma care: the TRISS method. Trauma Score and the Injury Severity Score. Trauma. 1987;27(4):370-8.

18. American College of Surgeons. Resources for optimal care of the injured patient. Chicago, III: American College of Surgeons, Committee on Trauma; 1990

19. Mulholland SA, Cameron PA, Gabbe BJ, Williamson OD, Young K Smith $\mathrm{KL}$, et al. pre-hospital prediction of the severity of blunt anatomic injury. J Trauma. 2008;64(3):754-60.

20. Sasser SM, Hunt RC, Faul M, Sugerman D, Pearson WS, Dulski T, et al. Guidelines for field triage of injured patients: recommendations of the National Expert Panel on Field Triage, 2011. MMWR Recomm Rep. 2012;61(RR-1):1-20.

21. Black JJ, Ward ME, Lockey DJ. Appropriate use of helicopters to transport trauma patients from incident scene to hospital in the United Kingdom: an algorithm. Emerg Med J. 2004;21(3):355-61.

22. Ringburg AN, de Ronde G, Thomas $S H$, van Lieshout EM, Patka P, Schipper IB. Validity of helicopter emergency medical services dispatch criteria for traumatic injuries: a systematic review. Prehosp Emerg Care. 2009;13(1):28-36.

23. Doucet J, Bulger E, Sanddal N, Fallat M, Bromberg W, Gestring M, et al. Appropriate use of helicopter emergency medical services for transport of trauma patients: guidelines from the Emergency Medical System Subcommittee, Committee on Trauma, American College of Surgeons. J Trauma Acute Care Surg. 2013;75(4):73441.

24. Diaz MA, Hendey GW, Bivins HG. When Is the helicopter faster? A comparison of helicopter and ground ambulance transport times. J Trauma. 2005;58(1):148-53.

25. Frankema SP, Ringburg AN, Steyerberg EW, Edwards MJ, Schipper $I B$, van Vugt $A B$. Beneficial effect of helicopter emergency medical services on survival of severely injured patients. $\mathrm{Br} J$ Surg. 2004;91(11):1520-6.

26. Ringburg AN, Spanjersberg WR, Frankema SP, Steyerberg EW, Patka P, Schipper IB. Helicopter emergency medical services (HEMS): impact on on-scene times. J Trauma. 2007;63(2):258-62. 
27. Dissmann PD, Le Clerc S. The experience of Teesside helicopter emergency services: doctors do not prolong pre-hospital on-scene times. Emerg Med J. 2007;24(1):59-62.

28. Melton JT, Jain S, Kendrick B, Deo SD. Helicopter Emergency Ambulance Service (HEAS) transfer: an analysis of trauma patient case-mix, injury severity and outcome. Ann R Coll Surg Engl. 2007;89(5):513-6.

29. Shatney CH, Homan SJ, Sherck JP, Ho CC. The utility of helicopter transport of trauma patients from the injury scene in an urban trauma system. J Trauma. 2002;53(5):817-22.

30. Bledsoe BE, Wesley AK, Eckstein M, Dunn TM, O'Keefe MF. Helicopter scene transport of trauma patients with nonlifethreatening injuries: a meta-analysis. J Trauma. 2006;60(6):12576; discussion 1265-6.
Received on 01/10/2013

Accepted for publication 20/12/2013

Conflict of interest: none.

Source of funding: Scientific Initiation Scholarship from the Foundation for Research Support of the State of São Paulo (FAPESP) gganted to Carina Fontana Francischini.

Mailing address:

Ricardo Cardoso Galesso

E-mail: rgalesso@hotmail.com 